\title{
Social anxiety symptoms and body image dissatisfaction in medical students: prevalence and correlates
}

\author{
Sintomas de ansiedade social e insatisfação com a imagem \\ corporal em estudantes de Medicina: prevalência e correlatos
}

Jacqueline M. Oliveira Regis', Ana Teresa A. Ramos-Cerqueira', Maria Cristina P. Lima', Albina R. Torres'

\begin{abstract}
Objective: Social anxiety disorder (SAD) and body image dissatisfaction (BID) are common problems among college students, but few studies focused on medical students. We aimed to estimate the prevalence, severity and correlates of SAD symptoms and BID among medical students of a Brazilian public university. Methods: A cross-sectional study with 479 students, using structured instruments: Social Phobia Inventory (SPIN), Body Shape Questionnaire (BSQ), and Beck Depression Inventory (BDI). Bivariate analyses were followed by logistic regression models to obtain independent predictors of SAD symptoms, BID and both outcomes combined. Results: Most students were single (99\%) and female (58.7\%). The prevalence rates of SAD symptoms (SPIN $\geq 19$ ) and BID (BSQ $\geq 81$ ) were $36.3 \%$ and $34.7 \%$, respectively. Depressive symptoms (BDI $\geq 19$ ) occurred in $8.8 \%$ of the sample. SAD symptoms were independently associated with: BID, thoughts of abandoning the course, difficulty making friends, depressive symptoms, and mental health treatment prior to university. Besides SAD symptoms, BID was associated with female sex, difficulty making friends, depressive symptoms, and body mass index (BMI). Seventy-eight students (16.3\%) presented SAD symptoms and BID, which was associated with female sex, difficulty making friends, dissatisfaction with the course, depressive symptoms and BMI. Conclusion: SAD symptoms and BID are common and related problems that should be screened for among medical students. The identification of specific correlates could contribute to the elaboration of preventive measures, minimizing the distress and negative impact of these mental health problems on relationships and academic performance.
\end{abstract}

\section{RESUMO}

Objetivo: $O$ transtorno de ansiedade social (TAS) e a insatisfação com a imagem corporal (IIC) são problemas comuns em estudantes universitários, mas poucos estudos avaliaram estudantes de Medicina. O objetivo do estudo foi estimar a prevalência, a gravidade e os correlatos de sintomas de TAS e IIC em estudantes de Medicina de uma universidade pública brasileira. Métodos: Estudo transversal com 479 estudantes utilizando os seguintes instrumentos de avaliação estruturados: Social Phobia Inventory (SPIN), Body Shape Questionnaire

1 São Paulo State University (Unesp), Botucatu Medical School, Department of Neurology, Psychology and Psychiatry, Botucatu, SP, Brazil.

Recebido em

$16 / 10 / 2017$

Aprovado em

$25 / 1 / 2018$ 


\author{
Palavras-chave \\ Estudantes de Medicina, \\ transtorno de ansiedade \\ social, fobia social, \\ insatisfação com a \\ imagem corporal, sintomas \\ depressivos.
}

(BSQ) e Beck Depression Inventory (BDI). Análises bivariadas foram seguidas de modelos de regressão logística para identificar preditores independentes de sintomas de TAS, IIC e ambos os desfechos combinados. Resultados: A maioria dos estudantes era solteira (99\%) e do sexo feminino (58,7\%). As prevalências de sintomas de TAS (SPIN $\geq 19$ ) e de ICC (BSQ $\geq 81$ ) foram de $36,3 \%$ e $34,7 \%$, respectivamente. Sintomas depressivos (BDI $\geq 19$ ) ocorreram em $8,8 \%$ da amostra. Sintomas de TAS associaram-se de modo independente com: IIC, pensamentos de abandonar o curso, dificuldade de fazer amigos, sintomas depressivos e tratamento de saúde mental antes de ingressar na universidade. Além de sintomas de TAS, IIC associou-se com sexo feminino, dificuldade de fazer amigos, sintomas depressivos e índice de massa corporal (IMC). Setenta e oito estudantes (16,3\%) apresentaram sintomas de TAS e IIC, o que se associou com sexo feminino, dificuldade de fazer amigos, insatisfação com o curso, sintomas depressivos e IMC. Conclusão: Sintomas de TAS e IIC são problemas comuns e inter-relacionados que devem ser rastreados em estudantes de Medicina. A identificação de correlatos específicos pode contribuir para a elaboração de medidas preventivas minimizando o sofrimento e o impacto negativo desses problemas de saúde mental nos relacionamentos e no desempenho acadêmico desses estudantes.

\section{INTRODUCTION}

High rates of distress, burnout and psychological or psychiatric problems have been reported among premedical students ${ }^{1-3}$. Possible reasons for this include difficulties in adjusting to the medical school environment (e.g. exposure to death and human suffering, increased responsibility and workload, lack of time for leisure activities, competitive academic environment, separation from family and friends), ethical conflicts (e.g. dehumanized approach to patients due to supervisors' modeling, student abuse), and personal problems (e.g. financial difficulties, life events)'. To date, however, most studies on mental health problems of pre-medical students have focused on common mental disorders and depressive symptoms or disorder.

Social anxiety disorder (SAD) symptoms and body image dissatisfaction (BID) are common problems among college students in general, leading to distress and depressive symptoms ${ }^{4-7}$, and negatively impacting their relationships and academic performance ${ }^{8}$.

$S A D$ is characterized by fear of social or performance situations in which the person is exposed to unfamiliar people or to possible scrutiny by others. In these situations the individual fears that he/she will act in a way that will be embarrassing and humiliating9. Among university students, SAD has been related to low self-esteem and body image distortion ${ }^{10}$, dysfunctional avoidance strategies ${ }^{11}$, and poor quality of life ${ }^{5}$. In this population, BID has been associated with female sex $x^{6,12-15}$ and higher body mass index (BMI) ${ }^{12,13,15-21}$.

To our knowledge, only one study with university students has specifically investigated the relationship between SAD and body image ${ }^{10}$, even though some studies addressed correlates of SAD symptoms and/or BID in the context of eating disorders ${ }^{6,22,23}$, body dysmorphic and obsessive- compulsive disorders ${ }^{24}$. The prevalence and correlates of cooccurring SAD symptoms and BID have never been explored in college students. Although several studies addressed BID in this population $6,12-14,16,17,19-21,25,26$, only four focused specifically on medical students, ${ }^{6,12,13,18}$. Moreover, several studies on BID included only female students ${ }^{16-20,25}$.

\section{Objectives and hypotheses}

We aimed to estimate the prevalence and severity of SAD symptoms and BID manifestations (separately and combined) among male and female pre-medical students of a Brazilian public university, and to investigate the independent correlates of these outcomes. We expected BID and SAD symptoms to be highly prevalent and significantly associated. We hypothesized that both outcomes would be associated with female sex, difficulty making friends, feelings of rejection, depressive symptoms and mental health treatment, whereas higher BMI would be specifically related to BID.

\section{METHODS}

\section{Study design}

This is a cross-sectional study, a subproject of a larger study entitled "Conditions of life and mental health of medical students of Botucatu Medical School - Unesp", described below.

\section{Subjects}

The sample was composed of 479 Brazilian pre-medical students from the 1st to 6th years of Botucatu Medical School (FMB) of São Paulo State University (Unesp), who were 
present when the research protocol was applied (May-June, 2011) and freely agreed to participate. The response rate was $88.7 \%$ (target population: 540 ). All participants signed a term of free, informed consent, which was separated from the research protocol to ensure data anonymity. The project was approved by the FMB Research Ethics Committee, under protocol no 581/10.

\section{Assessment instruments}

After being tested on six students, the self-report research protocol was applied during regular classes (average completion time: 30 min). Previously, we investigated which disciplines had the lowest absenteeism rates and scheduled the application with the teachers in charge. The main instruments are briefly described below:

1) a Questionnaire (available under request) to obtain data on demographics, social and academic situation (sex, age, religion, marital status, parents' educational level, living arrangements, monthly income and expenses, height, weight, satisfaction with the course, adaptation to the city, academic performance, scholarships, thoughts of abandoning the course, difficulty making friends, feelings of rejection by peers and support network), and psychiatric and/or psychological treatments before and after entering university, including psychopharmacs use;

2) Social Phobia Inventory (SPIN) ${ }^{27}$. The SPIN was used as a screening tool to assess social anxiety symptoms. The original inventory was previously translated and adapted into Portuguese, and validated for use in Brazilian college students ${ }^{28}$. It consists of 17 items to investigate anxiety, interference and avoidant behaviours related to several social situations in the previous week. Each item is scored according to a five-point Likert scale (0-4), the maximum score is 68 , and the cutoff point to define relevant social anxiety symptoms (sometimes denominated 'probable $S A D^{\prime}$ ) is $\geq 19$;

3) Body Shape Questionnaire (BSQ)29. This instrument evaluates the levels of dissatisfaction with body shape, self-depreciation of physical appearance and perception of being fat in the previous month. It has been previously validated for use in the Brazilian population ${ }^{30}$, including medical students ${ }^{13}$. The BSQ has 34 items with scores in a six-point Likert scale (1-6), indicating: 1, never; 2, rarely; 3, sometimes; 4, frequently; 5, very frequently; and 6, always. The maximum score is 204 and the levels of body image preoccupation are defined as: no preoccupation, < 81; mild preoccupation, 81-110; moderate preoccupation, 111-140; and severe preoccupation, > 140). The presence of BID was defined as BSQ score $\geq 81^{30}$;
4) Beck Depression Inventory (BDI) ${ }^{31}$. The $\mathrm{BDI}$ is a widely used instrument to measure the severity of cognitive, affective and somatic depressive symptoms in the previous week, both in psychiatric patients and in adults from the general population. The BDI consists of 21 items with scores ranging from 0 to 3 (maximum: 63). The severity levels are described as: < 10, no depression or minimal symptoms; 10-18, mild symptoms; 19-29, moderate symptoms; and 30 or more, severe symptoms ${ }^{32}$. The cutoff score $\geq 19$ differentiates cases of relevant depressive symptoms (or "depression") from non-cases.

\section{Statistical analysis}

The STATA 12 software $^{33}$ was used in the analyses. After descriptive analysis, bivariate analysis was conducted between the outcomes (SAD symptoms and BID) and all explanatory variables, using the chi-square test for qualitative variables and the non-parametric Mann-Whitney $U$ test for quantitative variables. Some variables were dichotomized into binary responses: adaptation to the city (totally adapted vs. partially or not adapted), academic performance (very good or good vs. regular, bad or very bad), and satisfaction with the course (totally satisfied vs. partially or not satisfied). The effect sizes of the associations were described as odds ratios (OR) with 95\% confidence intervals for qualitative variables, and Cohen's D for quantitative variables. Finally, three logistic regression models (for SAD symptoms, BID and both outcomes combined) were constructed. Each of them included the explanatory variables with a $p$ value $<0.25$ in the bivariate analysis (except for those presenting collinearity, as evaluated through the variance inflation factor), to obtain adjusted ORs. In the regression models (stepwise backward type), the independent variables were excluded one by one starting with the highest $p$ value, until all variables maintained statistical significance $(p<0.05)$.

\section{RESULTS}

The mean age of the students (58.7\% female, $99.0 \%$ single) was 22.5 years (SD \pm 2.6 ) and most of their fathers (74.4\%) and mothers (69.0\%) presented a college degree. The sociodemographic characteristics of the sample are described in Table 1.

The prevalence of SAD symptoms (SPIN $\geq 19$ ) was $36.3 \%$ (95\% Cl 32.0-40.6\%), some level of BID (BSQ $\geq 81$ ) was reported by $34.7 \%$ (95\% Cl 30.4-38.9\%) of the students, and $16.3 \%$ (95\% Cl 13.0-19.6\%) of them presented both SAD symptoms and BID. Relevant depressive symptoms (BDI $\geq$ 19) occurred in $8.8 \%$ (95\% Cl 6.2-11.3\%) of the sample, more frequently among third-year (16.3\%) and fifth-year (13.5\%) students (Table 2). 
Table 1. Sociodemografic characteristics of the sample (479 medical students)

\begin{tabular}{|c|c|c|}
\hline Quantitative variables & $\operatorname{Mean}(S D)$ & Median (range) \\
\hline Age (years) & $22.5(2.6)$ & $22.0(17-41)$ \\
\hline Weight (kg; self-report) & $66.3(14.1)$ & $63.0(40-120)$ \\
\hline Height (m; self-report) & $1.69(0.10)$ & $1.68(1.46-2.08)$ \\
\hline Body mass index & $23.0(3.3)$ & $22.5(16.4-39.3)$ \\
\hline Monthly income (MW) & 15.9 (11.1) & $12(1-90)$ \\
\hline Monthly expenses (MW) & $2.7(1.11)$ & $2.5(0.5-9.0)$ \\
\hline Categorical variables & N & $\%$ \\
\hline \multicolumn{3}{|l|}{ Sex } \\
\hline Male & 198 & 41.3 \\
\hline Female & 281 & 58.7 \\
\hline \multicolumn{3}{|l|}{ Marital status } \\
\hline Single & 474 & 99.0 \\
\hline Married or co-habiting & 4 & 0.8 \\
\hline Separated/divorced & 1 & 0.2 \\
\hline \multicolumn{3}{|l|}{ Living arrangements } \\
\hline With friend(s) & 278 & 58.0 \\
\hline Alone & 169 & 35.3 \\
\hline With parents & 17 & 3.6 \\
\hline With partner & 7 & 1.5 \\
\hline Students' residency & 2 & 0.4 \\
\hline 0thers & 6 & 1.2 \\
\hline \multicolumn{3}{|l|}{ Occupational status } \\
\hline Student (no work) & 458 & 95.6 \\
\hline Sporadic informal work & 14 & 2.9 \\
\hline Others & 7 & 1.5 \\
\hline \multicolumn{3}{|l|}{ Scholarship } \\
\hline No & 268 & 55.9 \\
\hline Yes & 211 & 44.1 \\
\hline \multicolumn{3}{|l|}{ Importance of religion } \\
\hline Important & 215 & 45.0 \\
\hline Moderately important & 143 & 29.9 \\
\hline Not important & 44 & 9.2 \\
\hline No religion & 76 & 15.9 \\
\hline \multicolumn{3}{|l|}{ Adaptation to the city } \\
\hline Totally adapted & 289 & 60.5 \\
\hline Partially adapted & 175 & 36.6 \\
\hline Not adapted & 14 & 2.9 \\
\hline \multicolumn{3}{|c|}{ Academic performance (self-evaluation) } \\
\hline Very good & 22 & 4.6 \\
\hline Good & 227 & 47.6 \\
\hline Regular & 176 & 36.9 \\
\hline Bad & 46 & 9.6 \\
\hline Very bad & 2 & 1.3 \\
\hline \multicolumn{3}{|l|}{ Satisfaction with the course } \\
\hline Totally satisfied & 357 & 74.9 \\
\hline Partially satisfied & 118 & 24.7 \\
\hline Not satisfied & 2 & 0.4 \\
\hline
\end{tabular}

SD: standard deviation; kg: kilograms; m: meters; MW: minimum wages.
The mean score in the SPIN was 15.6 (SD 12.4), in the BSQ 75.0 (SD 34.0) and in the BDI 9.1 (SD 0.3). The most common social anxiety symptom was fear of public speech (23.4\%), followed by being scared when criticized (19.4\%), doing anything to not be criticized (16.3\%) and fear of doing things when observed by others (15.9\%). The mean (SD) scores in the SPIN subscales were: 2.5 (3.2) for social inadequacy, 4.5 (3.9) for self-esteem, 3.7 (3.5) for physiological symptoms, 1.3 (1.5) for inferiority and 3.5 (3.1) for performance. The mean (SD) scores in the BSQ subscales were: 55.2 (26.5) for selfperception, 10.6 (5.5) for comparison, 8.0 (4.1) for attitudes and 2.5 (1.4) for severe alterations (data not shown).

The explanatory variables associated with the outcomes in the bivariate analysis are described in Table 3. In the logistic regression (Table 4), SAD symptoms were associated with: $\mathrm{BID}$ (OR 1.56), thoughts of abandoning the course (OR 1.53), difficulty making friends (OR 2.08), depressive symptoms (OR 2.78), and psychological or psychiatric treatment before entering university (OR 1.55). BID was associated with SAD symptoms (OR 1.84), female sex (OR 13.51), BMI (OR 1.38), difficulty making friends (OR 1.65), and depressive symptoms (OR 2.69). The 78 students that presented both SAD symptoms and BID were more likely to be females (OR 4.92), with high $\mathrm{BMI}(\mathrm{OR}$ 1.19), difficulty making friends (OR 2.86), dissatisfaction with the course (OR 1.99), and depressive symptoms (OR 2.77).

\section{DISCUSSION}

This is the first study investigating the prevalence, severity and correlates of SAD symptoms, BID dissatisfaction and the co-occurrence of these two outcomes in pre-medical students. Several explanatory variables were investigated, validated assessment instruments were used, and a high response rate was obtained.

Approximately one third of the students presented SAD symptoms and BID, and $16.3 \%$ had both problems. SAD symptoms and BID were significantly associated. Difficulties making friends and depressive symptoms were associated with the three outcomes; thoughts of abandoning the course and treatment before college were only associated with SAD symptoms, whereas female sex and BMI were only associated with BID and with the combined outcomes. Professional dissatisfaction was a significant correlate only when both outcomes were present.

These mental health problems were shown to be associated with distress, depressive symptoms, impaired peer relationships and academic performance in diverse college populations ${ }^{5-8,34}$. 
Table 2. Prevalence of social anxiety disorder (SAD) symptoms, body image dissatisfaction, both outcomes combined, and depressive symptoms in the sample, according to the medical school year

\begin{tabular}{|c|c|c|c|c|c|c|c|c|}
\hline Medical school year & $\begin{array}{l}\text { All years } \\
N=479\end{array}$ & $\begin{array}{c}1^{0} \text { year } \\
N=84(17.5 \%)\end{array}$ & $\begin{array}{c}2^{0} \text { year } \\
N=70(14.6 \%)\end{array}$ & $\begin{array}{c}3^{3} \text { year } \\
N=86(17.9 \%)\end{array}$ & $\begin{array}{c}4^{0} \text { year } \\
\mathrm{N}=75(15.7 \%)\end{array}$ & $\begin{array}{c}5^{0} \text { year } \\
N=74(15.5 \%)\end{array}$ & $\begin{array}{c}\quad 6^{0} \text { year } \\
N=90(18.8 \%)\end{array}$ & \multirow[t]{2}{*}{$p$} \\
\hline & $N(\%)$ & $N(\%)$ & $N(\%)$ & $N(\%)$ & $N(\%)$ & $N(\%)$ & $N(\%)$ & \\
\hline SAD symptoms & $174(36.3)$ & $34(40.5)$ & $23(32.9)$ & $32(37.2)$ & $21(28.0)$ & $29(39.2)$ & $35(38.9)$ & 0.58 \\
\hline BID & $166(34.7)$ & $24(28.6)$ & $23(32.9)$ & $36(41.9)$ & $26(34.7)$ & $29(39.2)$ & $28(31.1)$ & 0.46 \\
\hline SAD and BID & 78 (16.3) & $9(10.7)$ & $10(14.3)$ & $18(20.9)$ & $10(13.3)$ & $16(21.6)$ & $15(16.7)$ & 0.36 \\
\hline Depressive symptoms ${ }^{1}$ & $42(8.8)$ & $1(1.2)$ & $6(8.6)$ & $14(16.3)$ & $6(8.0)$ & $10(13.5)$ & $5(5.6)$ & 0.009 \\
\hline
\end{tabular}

BDI: Beck Depression Inventory; BSQ: Body Shape Questionnaire; SPIN: Social Phobia Inventory; SAD: Social Anxiety Disorder; BID: body image dissatisfaction; 1: Beck Depression Inventory score > 18.

Table 3. Factors associated with social anxiety disorder (SAD) symptoms, body image dissatisfaction and both outcomes combined in the bivariate analysis

\begin{tabular}{|c|c|c|c|c|}
\hline Categorical variables & $\begin{array}{c}\text { Total } \\
(\mathrm{N}=479)\end{array}$ & $\begin{array}{l}\mathrm{SAD}(\mathrm{N}=174) \\
\mathrm{OR}(95 \% \mathrm{CI})\end{array}$ & $\begin{array}{l}\mathrm{BID}(\mathrm{N}=166) \\
\mathrm{OR}(95 \% \mathrm{Cl})\end{array}$ & $\begin{array}{c}S A D \text { and } B I D(N=78) \\
O R(95 \%(I)\end{array}$ \\
\hline \multicolumn{5}{|l|}{ Sex } \\
\hline Male & $198(41.3)$ & 1 & 1 & 1 \\
\hline Female & $281(58.7)$ & $1.25(0.85-1.83)$ & $4.07(2.63-6.28)$ & $2.71(1.55-4.76)$ \\
\hline \multicolumn{5}{|l|}{ Lives alone } \\
\hline No & $315(65.8)$ & 1 & 1 & 1 \\
\hline Yes & $164(34.2)$ & $1.63(1.11-2.41)$ & $1.18(0.79-1.75)$ & $1.42(0.86-2.33)$ \\
\hline \multicolumn{5}{|c|}{ Difficulty in adaptation } \\
\hline No & $289(60.3)$ & 1 & 1 & 1 \\
\hline Yes & $190(39.7)$ & $1.81(1.24-2.66)$ & $1.21(0.83-1.78)$ & $1.56(0.96-2.53)$ \\
\hline \multicolumn{5}{|c|}{ Dissatisfaction with the course } \\
\hline No & $359(74.9)$ & 1 & 1 & 1 \\
\hline Yes & $120(25.1)$ & $1.35(0.89-2.07)$ & $0.97(0.63-1.50)$ & $1.88(1.12-3.16)$ \\
\hline \multicolumn{5}{|c|}{ Thoughts of abandoning the course } \\
\hline No & $290(60.5)$ & 1 & 1 & 1 \\
\hline Yes & $189(39.5)$ & $1.92(1.31-2.80)$ & $1.38(0.94-2.03)$ & $1.89(1.16-3.09)$ \\
\hline \multicolumn{5}{|c|}{ Regular/bad academic performance } \\
\hline No & $251(52.4)$ & 1 & 1 & 1 \\
\hline Yes & $228(47.6)$ & $1.30(0.89-1.88)$ & $1.20(0.82-1.75)$ & $1.62(0.99-2.65)$ \\
\hline \multicolumn{5}{|c|}{ Difficulty making friends } \\
\hline No & $349(73.0)$ & 1 & 1 & 1 \\
\hline Yes & $129(27.0)$ & $2.70(1.78-4.10)$ & $2.17(1.44-3.30)$ & $3.68(2.22-6.08)$ \\
\hline \multicolumn{5}{|l|}{ Feelings of rejection } \\
\hline No & $348(72.7)$ & 1 & 1 & 1 \\
\hline Yes & $131(27.3)$ & $2.57(1.70-3.89)$ & $2.10(1.39-3.18)$ & $2.76(1.67-4.56)$ \\
\hline \multicolumn{5}{|l|}{ SAD symptoms } \\
\hline No & $305(63.7)$ & ----- & 1 & ----- \\
\hline Yes & $174(36.3)$ & & $2.00(1.36-2.95)$ & \\
\hline \multicolumn{5}{|l|}{ BID } \\
\hline No & $313(65.3)$ & 1 & ---- & ---- \\
\hline Yes & $166(34.7)$ & $2.00(1.35-2.95)$ & & \\
\hline \multicolumn{5}{|c|}{ Depressive symptoms ${ }^{1}$} \\
\hline No & $437(91.2)$ & 1 & 1 & 1 \\
\hline Yes & $42(8.8)$ & $3.98(2.03-7.80)$ & $3.44(1.79-6.63)$ & $4.19(2.14-8.21)$ \\
\hline \multicolumn{5}{|c|}{ Treatment ${ }^{2}$ before college } \\
\hline No & $268(55.9)$ & 1 & 1 & 1 \\
\hline Yes & $211(44.1)$ & $1.75(1.20-2.55)$ & $1.67(1.14-2.45)$ & $1.93(1.18-3.15)$ \\
\hline \multicolumn{5}{|c|}{ Treatment ${ }^{2}$ after college } \\
\hline No & $190(39.7)$ & 1 & 1 & 1 \\
\hline Yes & $289(60.3)$ & $2.19(1.47-3.27)$ & $2.04(1.36-3.05)$ & $2.50(1.43-4.39)$ \\
\hline \multicolumn{5}{|c|}{ Use of pychopharmacs } \\
\hline No & $400(80.9)$ & 1 & 1 & 1 \\
\hline Yes & $69(19.1)$ & $1.40(0.83-2.35)$ & $1.67(1.05-2.67)$ & $1.82(0.98-3.35)$ \\
\hline
\end{tabular}


Table 4. Factors associated with social anxiety disorder (SAD) symptoms, body image dissatisfaction and both outcomes combined in the logistic regression

\begin{tabular}{|c|c|c|c|}
\hline & $\begin{array}{l}\text { SAD }(\mathrm{N}=174) \\
\text { OR }(95 \% \mathrm{Cl})\end{array}$ & $\begin{array}{l}\text { BID }(N=166) \\
\text { OR }(95 \% \mathrm{Cl})\end{array}$ & $\begin{array}{c}\text { SAD and BID }(\mathrm{N}=78) \\
\text { OR }(95 \% \mathrm{Cl})\end{array}$ \\
\hline SAD symptoms & ------ & $1.84(1.15-2.95)$ & ------ \\
\hline BID & $1.56(1.03-2.36)$ & ------ & ------ \\
\hline Female sex & NS & $13.51(7.25-25.17)$ & $4.92(2.51-9.64)$ \\
\hline Body mass index & NS & $1.38(1.26-1.52)$ & $1.19(1.10-1.30)$ \\
\hline Thoughts of abandoning the course & $1.53(1.02-2.29)$ & NS & NS \\
\hline Difficulty making friends & $2.08(1.34-3.22)$ & $1.65(1.01-2.72)$ & $2.86(1.65-4.94)$ \\
\hline Dissatisfaction with the course & NS & NS & $1.99(1.12-3.55)$ \\
\hline Depressive symptoms' & $2.78(1.37-5.66)$ & $2.69(1.19-6.09)$ & $2.77(1.30-5.91)$ \\
\hline Treatment ${ }^{2}$ before college & $1.55(1.04-2.31)$ & NS & NS \\
\hline
\end{tabular}

SAD: Social anxiety disorder; BID: body image dissatisfaction; OR: odds ratio; Cl: confidence interval;

1: Beck Depression Inventory score > 18; 2: Mental health (psychological/psychiatric) treatment; NS: Not significant.

\section{Prevalence rates of SAD symptoms and BID}

The high prevalence of SAD symptoms obtained (36.3\%) is similar to that described in college students of various courses in Jordan (30.6\%) using the SPIN ${ }^{35}$ and in Australia (30\%) using the Mini-SPIN, with only three items ${ }^{36}$. The fact that the SPIN is a highly sensitive screening tool may partly justify the higher rates of SAD symptoms obtained, compared to studies using diagnostic instruments. However, so far no study has focused exclusively on medical students. Among 2,319 Brazilian students from several university courses (13\% Medicine), the prevalence of SAD symptoms was $20.6 \%$ in the screening phase using the Mini-SPIN and $11.6 \%$ in the diagnostic phase (6\% among medical students) using the Structured Clinical Interview for DSM-IV ${ }^{8}$. In college students from various courses in Turkey ${ }^{10}$ and Nigeria ${ }^{5}$ the prevalence rates of SAD were around 9\% (lifetime) and 8\% (one-year), using diagnostic interviews. Using screening instruments, the prevalence among college students varied from $16.1 \%$ in Switzerland ${ }^{11}$ to $54.2 \%$ in Oman ${ }^{37}$.

Of note, the most frequent manifestations of social anxiety were fear of speaking in public $5^{5,8}$ and of being criticized or observed. These fears may impact the performance of medical students, since the academic environment is usually very competitive and demanding, with frequent public presentations and practical tests. Perfectionist personality traits can also increase the distress of these students, who frequently have difficulties in accepting personal failures ${ }^{38}$. So, actively screening for SAD symptoms can be especially important in this population, since SAD sufferers usually underreport their symptoms and avoid seeking professional assistance ${ }^{39}$.

The prevalence of BID (37.4\%) was similar to that (32.5\%) described in Chinese medical students ${ }^{40}$, but much lower than among Pakistani medical students, $78.8 \%$ of which reported dissatisfaction with some aspect of their appearance ${ }^{26}$. In Brazil, the prevalence rates among medical students were $14.3 \%{ }^{13}, 27.7 \%{ }^{18}, 35.6 \%{ }^{12}$ and $47.0 \%{ }^{21}$. Among college students from different countries the rates of BID vary widely from $10.1 \%^{15}$ to $74.3 \%{ }^{4}$. It is important to note, however, that some studies included only females s, $16-18,20,21,25^{2}$ and used different instruments or BSQ cutoff points ${ }^{13,15}$, methodological aspects that affect prevalence estimates. Moreover, some studies focused on body dysmorphic disorder (BDD), a related but different construct from BID.

The association between SAD symptoms and BID has been described in previous studies, 10,24,40,41. SAD symptoms (but not OCD or panic disorder symptoms) were associated with body image disturbance, reduced satisfaction with one's appearance, and reduced feelings of attractiveness in the study by Aderka et al. ${ }^{41}$. According to these authors, distorted and negative self-perception could be a cognitive pattern underlying both BID and SAD. Individuals who present SAD usually have low self-esteem, are dissatisfied with their performance and their physical appearance, characteristics that usually have a negative impact on social relationships ${ }^{10}$. Indeed, low self-esteem, social fears and avoidance, and excessive concern over evaluations by others are common features of both conditions, which also share beliefs that a negative evaluation by others will be catastrophic ${ }^{24}$. Some overlap concerning dysfunctional beliefs has been described in patients with SAD and BDD - a disorder that has BID as its essential feature -, and elevated levels of social appearance anxiety can be a risk factor for SAD ${ }^{24}$. In fact, conditional beliefs about the self are a transdiagnostic construct present in SAD (e.g. "If people don't accept me I'm worthless") and BDD (e.g. "My value as a person depends on how / look"), and SAD- conditional beliefs predicted BDD stressor responding in a recent study by Parsons et al.24. Interestingly, Westerns cultures conceptualize SAD and BDD as distinct disorders, whereas Eastern cultures often conceptualize BDD as a subtype of SAD, due to their similarities. 


\section{Correlates of SAD symptoms and BID}

\section{Female Sex}

Women were more likely to present BID (and both outcomes combined), but not SAD symptoms. According to Conti et al. ${ }^{42}$, "sociocultural influences, media pressures and the incessant search for an ideal body pattern associated with accomplishments and happiness are among the causes of altered perception of body image, generating dissatisfaction, especially for females". Of note, "difficult making friends", a central aspect of SAD, was significantly associated with BID in this study. Female students with high levels of social anxiety can be more vulnerable to media pressures regarding ideal patterns of body image ${ }^{7}$. Accordingly, compared to males, females in our study were 13.5 times more likely to present BID and almost five times more likely to present both problems, while SAD symptoms did not differ between genders. The same association between BID and female sex was observed by other researchers among general university ${ }^{14,15}$ and medical students $5^{6,12,13}$.

\section{Body mass index}

The literature is consistent regarding the association between BID and higher BMI 12,13,15-21. In Brazil, female medical students with normal BMI presented higher mean scores in the BSQ compared to those with low BMI' ${ }^{12}$. Costa \& Vasconcelos ${ }^{20}$ described an association between BID, BMI and weight loss diets among females of several university courses. This is relevant, since BID and restrictive diets are important risk factors for eating disorders ${ }^{20,43}$ a serious mental health problem that has been investigated in college students by several authors $6,17,18,22,43,44$.

\section{Thoughts of abandoning the course}

Students that reported thoughts of abandoning the medical coursewere more likely to presentSAD symptoms. Accordingly, Stein et al. ${ }^{45}$ reported that individuals with SAD were twice as likely to report interference in education and to drop out of school due to social difficulties. Among patients presenting anxiety disorders, 49\% reported early school dropout and $24 \%$ of them stated that anxiety was the main reason for this decision ${ }^{46}$. In fact, those who left school prematurely were more likely to present $S A D$, and the main reasons for dropping out were feeling very nervous at school and difficulty speaking in front of colleagues ${ }^{46}$. Abandoning medical school is a very serious decision, probably involving much distress, doubt and contradictory feelings, since the course is highly disputed and valued in our society. These thoughts have been previously associated with burnout ${ }^{3}$, depressive symptoms ${ }^{47,48}$ and suicidal ideation in this population ${ }^{47}$.

\section{Difficulty making friends}

Students that had difficulties making friends were twice as likely to have SAD symptoms, similarly to the results obtained in two large community-based studies in the USA - National Comorbidity Survey-Replication and National Survey of American Life -, in which SAD was the only diagnosis associated with poor quality relationships with friends ${ }^{49}$. Social avoidant behaviours and social isolation are core features of SAD, but difficulty making friends was also correlated with BID, suggesting that worries about one's physical appearance also negatively affect peer relationships in this population.

\section{Dissatisfaction with the course}

Although this variable was not independently associated with SAD symptoms or BID when separately analysed, it was a significant correlate among students presenting both outcomes. It is possible the combination of these problems increases the negative impact on these students, affecting the appreciation of their professional choice. However, no causal relations can be inferred due to the cross-sectional nature of the study.

\section{Depressive symptoms}

Relevant depressive symptoms were the strongest predictor of SAD symptoms in the logistic regression. Students with depressive symptoms were almost three times more likely to present SAD symptoms, probably leading to even higher levels of distress and functional impairment. The association between SAD and depression was also described among medical students in Nigeria ${ }^{5}$, in patients attending general care setting $s^{50}$ and in community samples ${ }^{51,52}$. Weiller et al. ${ }^{50}$ observed that patients with SAD were twice as likely to present comorbid depression and that in 75\% SAD predated the onset of depressive symptoms. Although the cross-sectional design does not permit temporal assumptions, prospective studies have shown that SAD is an early or adolescent-onset condition that consistently and substantially increases the risk for subsequent depression ${ }^{51,52}$.

Regarding BID, it was also associated with depressive symptoms and low self-esteem in psychology students in the USA and France ${ }^{4,7}$. Likewise, BID was associated with depression in Chinese medical students $5^{6,40}$

\section{Treatment before university}

Mental health treatment (either psychological or psychiatric) before entering medical school was only associated with SAD symptoms. This finding suggests these symptoms indeed have an early onset and are associated with considerable distress and/or interference, leading to help seeking early in life, which may also be due to frequently co-occurring depressive symptoms.

\section{Limitations}

The cross-sectional design precludes inferences regarding cause and effect relationships between variables. Data on 
height and weight were self-reported and, therefore, BMl is subject to information bias. A comparison group was not included (e.g. university students from other courses) and some of the correlates identified (e.g. difficulty making friends, depressive symptoms) may not be specific to the outcomes investigated. Despite being validated for use with Brazilian college students, the SPIN is not a diagnostic tool for SAD, and the high prevalence of SAD symptoms obtained suggests that a score of $\geq 19$ is too liberal in terms of SAD diagnosis. The possibility of type 1 error cannot be discarded, due to the high number of explanatory variables investigated. The generalization of the results for pre-medical students of other (public and private) institutions - especially from other countries - should be cautious, due to different sociodemographic and cultural characteristics.

\section{CONCLUSIONS}

The prevalence of SAD symptoms and BID was very high among pre-medical students (approximately one third of the sample), and $16.3 \%$ presented both conditions. Thus, it is important to screen for these frequent and often secret problems in this population. Moreover, SAD symptoms and BID were significantly associated, suggesting possible overlap regarding clinical features and/or underlying dysfunctional beliefs, or common etiological influences.

Difficulty making friends and depressive symptoms were associated with all outcomes (SAD symptoms, BID and both problems), but some specific correlates were also identified. Thoughts of abandoning the course and treatment before entering university were only associated with SAD symptoms, whereas female sex and BMI were only associated with BID and with the outcomes combined.

The results of this study could contribute to more awareness and identification of these mental health problems among medical students, and to the elaboration of preventive and therapeutic measures. These approaches should hopefully attenuate the emotional suffering and the negative impact of SAD symptoms and BID on psychosocial functioning and academic achievements, and prevent further psychopathological manifestations in these students.

\section{INDIVIDUAL CONTRIBUTIONS}

Jacqueline M. Oliveira Regis - Contributed to writing the research protocol, analysis and interpreting data, literature searches, revising the article critically and approved its final version.

Ana Teresa A. Ramos-Cerqueira - Contributed to conception of the study, writing the research protocol, revising the article critically and approved its final version.
Maria Cristina P. Lima - Contributed to conception of the study, revising the article critically and approved its final version.

Albina R. Torres - Contributed to conception of the study, writing the research protocol, analysis and interpreting data, writing the first draft of the article and approved its final version.

\section{CONFLICTS OF INTEREST}

The authors have no conflicts of interest to declare.

\section{ACKNOWLEDGEMENTS}

We are especially grateful to the students who participated in the study.

\section{ROLE OF FUNDING SOURCES}

The study has received financial support from the São Paulo Research Foundation (Fapesp, grant number 21832-9, 2011, in the name of the author MCPL).

\section{REFERENCES}

1. Dyrbye LN, Thomas MR, Shanafelt TD. Medical student distress: causes, consequences, and proposed solutions. Mayo Clin Proc. 2005;80(12):1613-22.

2. Dyrbye LN, Thomas MR, Shanafelt TD. Systematic review of depression, anxiety, and other indicators of psychological distress among U.S. and Canadian medical students. Acad Med. 2006;81(4):354-73.

3. Dyrbye LN, Thomas MR, Power DV, Durning S, Moutier C, Massie FS Jr, et al. Burnout and serious thoughts of dropping out of medical school: a multi-institutional study. Acad Med. 2010;85(1):94-102.

4. Bohne A, Wilhelm S, Keuthen NJ, Florin I, Baer L, Jenike MA. Prevalence of body dysmorphic disorder in a German college student sample. Psychiatry Res. 2002;109(1):101-4.

5. Bella TT, Omigbodun 00. Social phobia in Nigerian university students: prevalence, correlates and co-morbidity. Soc Psychiatry Psychiatr Epidemiol. 2009;44(6):458-63.

6. Liao Y, Knoesen NP, Castle DJ, Tang J, Deng Y, Bookun R, et al. Symptoms of disordered eating, body shape, and mood concerns in male and female Chinese medical students. Compr Psychiatry. 2010;51(5):516-23.

7. Rodgers RF, Salès P, Chabrol H. Psychological functioning, media pressure and body dissatisfaction among college women. Eur Rev Appl Psychol. 2010;60:89-95.

8. Baptista CA, Loureiro SR, de Lima Osório F, Zuardi AW, Magalhães PV, Kapczinski F, et al. Social phobia in Brazilian university students: prevalence, under-recognition and academic impairment in women. J Affect Disord. 2012;136(3):857-61.

9. American Psychiatric Association (APA). Diagnostic and Statistical Manual of Mental Disorders - DSM-5. 5th ed. Washington, DC: APA; 2013.

10. Izgiç F, Akyüz G, Doğan 0, Kuğu N. Social phobia among university students and its relation to self-esteem and body image. Can J Psychiatry. 2004;49(9):630-4.

11. Tillfors M, Furmark T. Social phobia in Swedish university students: prevalence, subgroups and avoidant behavior. Soc Psychiatry Psychiatr Epidemiol. 2007;42(1):79-86. 
12. Moreira $L A C$, Azevedo ABG, Queiroz D, Moura L, Santo DE, Cruz R, et al. Body image in a sample of undergraduate medical students from Salvador, Bahia, Brazil. J Bras Psiquiatr. 2005;54(4):295-7.

13. Di Pietro M, Silveira DX. Validade interna, dimensionalidade e desempenho da escala Body Shape Questionnaire em uma população de estudantes universitários brasileiros. Rev Bras Psiquiatr. 2009;31(1):21-4.

14. Akbarbegloo M, Habibpur Z, Motaarefi H. Perception of body image in students and related factors. Social Sci. 2010;5(4):368-72.

15. Miranda VPN, Filgueiras JF, Neves CM, Teixeira PC, Ferreira MEC. Insatisfação corporal em universitários de diferentes áreas de conhecimento. J Bras Psiquiatr. 2012,61:25-32.

16. Bosi MLM, Luiz RR, Morgado CMC, Costa MLS, Carvalho RJ. Autopercepção da imagem corporal entre estudantes de nutrição: um estudo no município do Rio de Janeiro. J Bras Psiquiatr. 2006;55(2):108-13.

17. Bosi MLM, Uchimura KY, Luiz RR. Eating behavior and body image among psychology students. J Bras Psiquiatr. 2009;58(3):150-5.

18. Bosi MLM, Nogueira JAD, Uchimura KY, Luiz RR, Godoy MGC. Eating behavior and body image among medicine students. Rev Bras Educ Med. 2014;38(2):243-52.

19. Alvarenga MS, Philippi ST, Lourenço BH, Sato PM, Scagliusi FB. Insatisfação com a imagem corporal em universitárias brasileiras. J Bras Psiquiatria. 2010;59(1):44-51.

20. Costa LCF, Vasconcelos FAG. Influência de fatores socioeconômicos, comportamentais e nutricionais na insatisfação com a imagem corporal de universitárias em Florianópolis, SC. Rev Bras Epidemiol. 2010;13(4):665-76.

21. Garcia L, Milagres $\mathrm{OG}$, Mourão L, Assis M, Palma A. Autopercepção da imagem corporal em estudantes de Educação Física e Medicina. Rev Bras Ativ Fís Saúde. 2011;16(1):25-30.

22. Sepúlveda AR, Carrobles JA, Gandarillas A, Poveda J, Pastor V. Prevention program for disturbed eating and body dissatisfaction in a Spanish university population: a pilot study. Body Image. 2007;4(3):317-28.

23. Levinson CA, Rodebaugh TL. Social anxiety and eating disorder comorbidity: the role of negative social evaluation fears. Eat Behav. 2012;13(1):27-35.

24. Parsons EM, Straub KT, Smith AR, Clerkin EM. Body dysmorphic, obsessive-compulsive, and social anxiety disorder beliefs as predictors of in vivo stressor responding. J Nerv Ment Dis. 2017;205(6):471-9.

25. Cansever A, Uzun 0 , Dönmez E, Ozşahin A. The prevalence and clinical features of body dysmorphic disorder in college students: a study in a Turkish sample. Compr Psychiatry. 2003:44(1):60-4.

26. Taqui AM, Shaikh M, Gowani SA, Shahid F, Khan A, Tayyeb SM, et al. Body dysmorphic disorder: gender differences and prevalence in a Pakistani medical student population. BMC Psychiatry. 2008;8:20.

27. Connor KM, Davidson JRT, Churchill LE, Sherwood A, Weisler RH, Foa E. Psychometric properties of the Social Phobia Inventory (SPIN): new self-rating scale. Br J Psychiatry. 2000;176(4):379-86.

28. Osório FL, Crippa JAS, Loureiro SR. Cross-cultural validation of the Brazilian Portuguese version of the Social Phobia Inventory (SPIN): study of the items and internal consistency. Rev Bras Psiquiatr. 2009;31(1):25-9.

29. Cooper PJ, Taylor MJ, Cooper Z, Fairbum CG. The development and validation of the body shape questionnaire. Int J Eat Disord. 1987;6(4):485-94.

30. Conti MA, Cordás TA, Latorre MRDO. A study of the validity and reliability of the Brazilian version of the Body Shape Questionnaire (BSQ) among adolescents. Rev Bras Saude Mater Infant. 2009;9(3):331-8.

31. Beck AT, Ward CH, Mendelson M, Mock J, Erbaugh J. An inventory for measuring depression. Arch Gen Psychiatry.1961;4:561-71.
32. Beck AT, Steer RA, Garbin MG. Psychometric properties of the Beck Depression Inventory: twenty-five years of evaluation. Clin Psychol Rev. 1988;8(1):77-100.

33. Statacorp, 2011. Stata Statistical Software: Release 12.0 .

34. Bohne A, Keuthen NJ, Wilhelm S, Deckersbach T, Jenike MA. Prevalence of symptoms of body dysmorphic disorder and its correlates: a cross-cultural comparison. Psychosomatics. 2002;43(6):486-90

35. Mustafa RB, Hamdan-Mansour AM, Hijazeen JK, Abed HS, Abdallah FW, El-Haija HMA, et al. Social phobia among university students in Jordan. Life Sci J. 2014;11:93-8.

36. Wilson I. Screening for social anxiety disorder in first year university students - a pilot study. Aust Fam Physician. 2005;34(11):983-4.

37. Al-Hinai SS, Al-Saidy 0, Dorvlo ASS, Al-Riyami BMS, Bhargava K, Northway MG, et al. Culture and prevalence of social phobia in a college population in Oman. In: Landow MV, editor. College students: mental health and coping strategies. New York: Nova Science Publishers; 2006. p. 115-32.

38. Cataldo Neto A, Cavalet D, Bruxel DM, Kappes DS, Silva DOF. 0 estudante de medicina e 0 estresse acadêmico. Rev Med PUCRS. 1998;8(1):6-12.

39. den Boer JA. Social anxiety disorder/social phobia: epidemiology, diagnosis, neurobiology, and treatment. Compr Psychiatry. 2000;41(6):405-15.

40. Liao Y, Knoesen NP, Deng Y, Tang J, Castle DJ, Bookun R, et al. Body dysmorphic disorder, social anxiety and depressive symptoms in Chinese medical students. Soc Psychiatry Psychiatr Epidemiol. 2010;45(10):963-71.

41. Aderka IM, Gutner CA, Lazarov A, Hermesh H, Hofmann SG, Marom S. Body image in social anxiety disorder, obsessive-compulsive disorder, and panic disorder. Body Image. 2014;11(1):51-6.

42. Conti MA, Frutuoso MFP, Gambardella AMD. Excesso de peso e insatisfação corporal em adolescentes. Rev Nutr. 2005;18(4):491-7.

43. Jaeger B, Ruggiero GM, Edlund B, Gomez-Perretta C, Lang F, Mohammadkhani P, et al. Body dissatisfaction and its interrelations with other risk factors for bulimia nervosa in 12 countries. Psychother Psychosom. 2002;71(1):54-61.

44. Legnani RFS, Legnani E, Pereira EF, Gasparotto GS, Vieira LF, Campos W. Transtornos alimentares e imagem corporal em acadêmicos de Educação Física. Motriz Rev Educ Fis. 2012;18:84-91

45. Stein MB, Torgrud LJ, Walker JR. Social phobia symptoms, subtypes, and severity: findings from a community survey. Arch Gen Psychiatry. 2000;57(11):1046-52.

46. Van Ameringen M, Mancini C, Farvolden P. The impact of anxiety disorders on educational achievement. J Anxiety Disord. 2003;17(5):561-71.

47. Dyrbye LN, Harper W, Durning SJ, Moutier C, Thomas MR, Massie FS Jr, et al. Patterns of distress in US medical students. Med Teach. 2011;33(10):834-9.

48. Costa EFO, Santana YS, de Abreu Santos ATR, Nogueira Martins LA, Melo EV, Andrade TM. Sintomas depressivos entre internos de medicina em uma universidade pública brasileira. Rev Assoc Med Bras. 2012;58(1):53-9.

49. Rodebaugh TL. Hiding the self and social anxiety: the core extrusion schema measure. Cogn Ther Res. 2009:33:90-109.

50. Weiller E, Bisserbe JC, Boyer P, Lepine JP, Lecrubier Y. Social phobia in general health care: an unrecognised undertreated disabling disorder. Br J Psychiatry. 1996;168(2):169-74.

51. Beesdo K, Bittner A, Pine DS, Stein MB, Höfler M, Lieb R, et al. Incidence of social anxiety disorder and the consistent risk for secondary depression in the first three decades of life. Arch Gen Psychiatry. 2007;64(8):903-12.

52. Ohayon MM, Schatzberg AF. Social phobia and depression: prevalence and comorbidity. J Psychosom Res. 2010;68(3):235-43. 